\title{
Prediction of human papilloma virus antigen in cervical squamous epithelium by koilocyte nuclear morphology and "wart scores": confirmation by immunoperoxidase
}

\author{
KAREN MCLEOD \\ From the Department of Pathology, University of Edinburgh Medical School, Edinburgh
}

SUMMARY Koilocytes (balloon cells) in cervical squamous epithelium can be distinguished by their nuclear morphology as members of two populations $\mathbf{A}$ and $\mathbf{B}$. The proposition that population $\mathbf{A}$ was infected with human papilloma virus (HPV) and population B was not, was examined immunohistologically. A peroxidase-antiperoxidase technique using polyclonal HPV antibody failed to support the hypothesis and showed small fractions of both populations to be infected with the virus $(A=5$ of $25 ; B=2$ of 19$)$.

Nuclear morphology alone is thus inadequate to distinguish infected from non-infected koilocytes, or balloon cells. When a number of well established histological changes in squamous epithelia infected with HPV were examined, graded, and summated to obtain a "wart score," however, a reasonably accurate prediction of HPV infection emerged.

Koilocytes are squamous cells characterised by their swollen ballooned appearance and clear vacuolated cytoplasm. ${ }^{1}$ They are often found in cervical squamous epithelium and are considered to be reasonably good markers for human papilloma virus (HPV) infection, being features both of Condyloma acuminata and of "flat warts". ${ }^{23}$ As there is such a strong association between HPV and cervical cancer, ${ }^{4-6}$ the identification of HPV in cervical squamous epithelium is important, both epidemiologically and for studies of the role of HPV as a potential carcinogen.

Doubt has been cast, however, on the validity of koilocytes as a histological marker of HPV infection. Clear cells can be seen in cervical squamous epithelium for other reasons, such as infection by Trichomonas, ${ }^{7}$ and even as artefact due to tissue processing. ${ }^{8}$ It is evident that it would be useful to have a simple and reliable histological means by which the pathologist could distinguish koilocytes infected with HPV in cervical squamous epithelium from other non-infected clear cells.

Study of koilocytes in cervical squamous epithelium led to the observation that there seem to be two populations of koilocytes, distinguishable by

Accepted for publication 10 September 1986 differences in nuclear morphology: one population shows more irregular bizarre nuclei; and the other shows more round regular nuclei. An hypothesis was proposed that the population of clear cells with bizarre irregular nuclei, termed " $A$ " koilocytes (fig 1), were the true HPV infected cells, whereas the population of clear cells with rounded, regular, nuclei, termed "B" koilocytes (fig 2), were non-infected cells, vacuolated for other reasons.

A study was set up to test the hypothesis. Sections of "A" and "B" koilocytes were selected and a search made for HPV using an immunoperoxidase technique specific for HPV antigen. Thus it was hoped to establish whether the hypothesis was correct. In addition, the epithelial environments of " $A$ " and " $B$ " koilocytes were examined to determine if there were differences between the two populations in relevant respects other than nuclear morphology. Therefore, from the entire study it was hoped to establish whether the differences between " $A$ " and " $B$ " koilocytes were due to a difference in HPV infection, or whether they existed for other reasons.

\section{Material and methods}

Sections of formalin fixed cervical squamous epithelium, stained by haematoxylin and eosin, were 


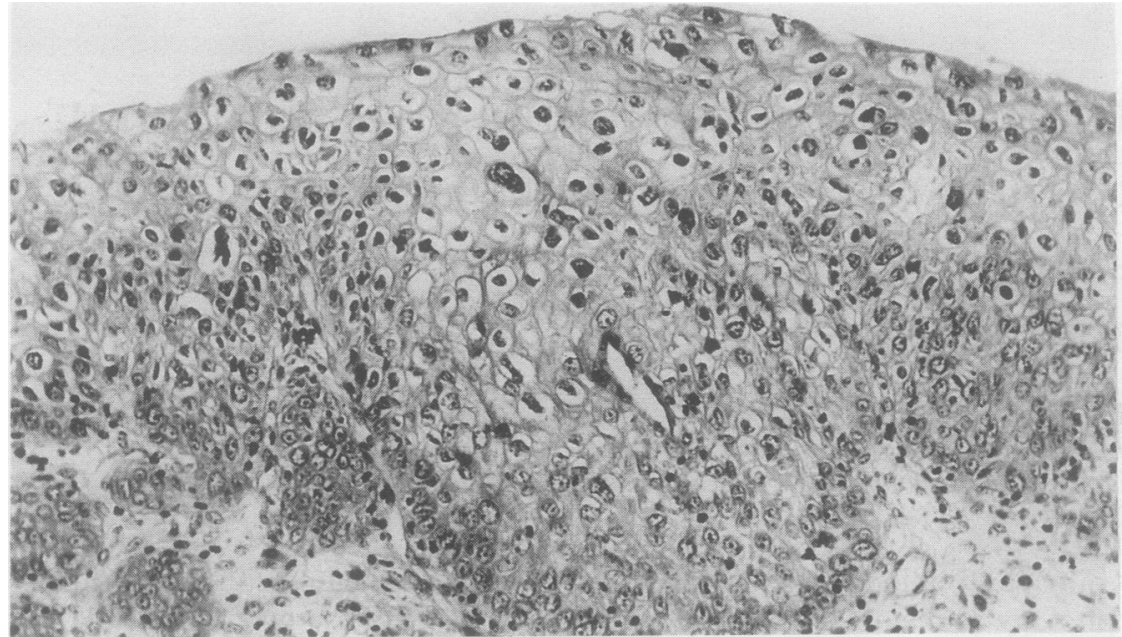

Fig 1 "A" koilocytes: expanded superficial "balloon" cells showing large, bizarre, sometimes twisted nuclei with relatively pale, granular chromatin. (Haematoxylin and eosin.) $\times 160$.

obtained and examined for the presence of koilocytes. The koilocytes were assessed as type A or type B, by two independent observers, according to the nuclear morphological criteria listed in table 1 .

Division into two types of koilocyte resulted in a study sample of 25 sections of " $A$ " koilocytes from 24 patients (two of the sections were from the same patient but from different biopsy specimens) and 19 sections of " $B$ " koilocytes were from 18 patients (two of the sections were from the same patient but from different biopsy specimens). The two independent observers agreed in all but one case, which was finally assessed as type " $B$ ".

\section{HISTOPATHOLOGICAL FEATURES OF HPV} INFECTION

The selected stained sections were assessed to determine the degree to which other well established histological features of HPV infection (or "warts") were present. Each of the individual features was scored on a scale $0-3$, and the individual scores were added to give a total "wart score." The total wart scores were assessed before staining for HPV to avoid observer bias once it was known which sections were HPV positive. Table 2 shows the histopathological features and scoring system, which are similar to those used by Reid et al. $^{4}$

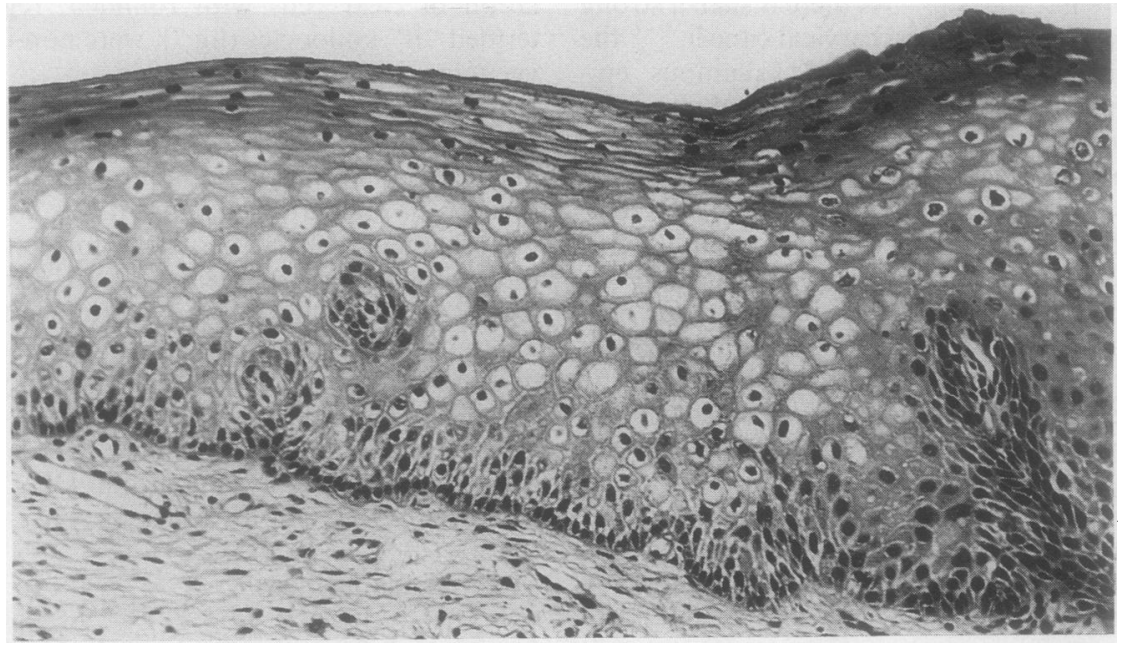

Fig 2 "B" koilocytes: expanded superficial "balloon cells"with mainly round, dense, nuclei (reminiscent of those of the lymphocyte). (Haematoxylin and eosin). $\times 160$. 
Table 1 Nuclear morphology of " $A$ " and " $B$ " koilocytes

\begin{tabular}{lll}
\hline & Type A & Type B \\
\hline Size & Larger than normal & Normal or small \\
Shape & $\begin{array}{l}\text { Bizarre-angulated, } \\
\text { twisted or "screwed up" }\end{array}$ & Round to oval \\
Outline & Irregular & Regular \\
Staining & $\begin{array}{l}\text { Irregular, often granular } \\
\text { appearance }\end{array}$ & $\begin{array}{l}\text { Dense, homogeneous, } \\
\text { often pyknotic } \\
\text { appearance }\end{array}$ \\
\hline
\end{tabular}

The degree of koilocytosis in each section was assessed separately from the total wart score. It consisted of a score for the abundance of koilocytes and a score for the extent of vacuolation within the koilocytes (table 3 ).

\section{Degree of dysplasia}

The most severe degree of dysplasia coincident with, or adjacent to, the koilocytes was assessed by a pathologist with a special interest in cervical pathology.

The following grading system was used ${ }^{910}$ : no dysplasia or mild dysplasia (CIN I); moderate dysplasia (CIN II); severe dysplasia and carcinoma in situ (CIS). (Severe dysplasia and CIS are both equivalent to CIN III).

The method outlined by Fletcher ${ }^{10}$ was adopted to overcome the difficulties of grading dysplasias in the presence of koilocytes. In two of the sections of " $A$ " koilocytes, however, the extent of koilocytosis was so great that it was impossible to grade the degree of dysplasia. These two sections were considered to be plenary koilocytosis. ${ }^{10}$

\section{HPV nuclear antigen}

Duplicate sections were cut from the paraffin embedded tissue blocks and stained for HPV nuclear viral antigen by the well established indirect immunoperoxidase (PAP) technique, ${ }^{11}$ using a polyclonal antibody to HPV antigens (DakoPatts).

The specificity and most suitable titre of the antibody were determined by applying a series of dilutions to wart and non-wart tissue.

In each PAP run a section of a facial skin wart was included as a known positive control and a section of normal cervix as a negative control. In addition, for each test section, a duplicate section was included, where normal rabbit serum was applied in place of the rabbit anti-HPV serum.

A positive result was regarded as the presence of brown granular staining deposits in cell nuclei (fig 3). Positive sections were scored according to the number and distribution of stained cells: $+=$ cells with positive nuclei scattered far apart; $++=$ cells with posi- tive nuclei, in aggregates; $+++=$ cells with positive nuclei, in dense aggregates.

\section{Results}

TOTAL WART SCORE

"A" koilocytes were found to be associated with higher total wart scores than "B" koilocytes (fig 4). "A" koilocytes were also associated with higher scores for each of the individual features comprising the total wart score.

\section{DEGREE OF DYSPLASIA}

Type "A" koilocytes were found to be associated with significantly higher degrees of dysplasia than type "B" koilocytes (figs $5 \mathrm{a}$ and $\mathrm{b}$ ).

KOILOCYTES AND HPV NUCLEAR VIRAL ANTIGEN HPV nuclear viral antigen was shown in five of the 25 sections of " $A$ " koilocytes and two of the 19 sections of "B" koilocytes. Two of the sections of "A" koilocytes positive for virus were those from the same patient but from different biopsy specimens. The two

Table 2 Total wart score

1 Acanthosis: Epidermal hyperplasia

(a) Basal cell hyperplasia

Score 0 Normal, single layer of well orientated, well spaced cuboidal cells

1 Slight proliferation of basal cells to give an increased number, but still a single layer

2 Proliferation to give two to three layers

3 More than three layers of basal cells

(b) Intermediate cell hyperplasia

Score 0 Normal, polygonal cells, well spaced, with intercellular bridges, confined to lower half of epithelium

1 Minimal proliferation to give increase in cell number, but confined to lower half

2 Proliferation to take up between half and two thirds of the epithelium

3 Proliferation to extend beyond two thirds of the epithelium

2 Parakeratosis: Keratinisation of nucleated superficial cell layers 0 None

1 One to two layers

2 Two to three layers

3 More than three layers

3 Orthokeratosis: Keratinisation of non-nucleated epithelial surface 0 None

1 Thin layer

2 Moderate layer

3 Thick layer

4 Dyskeratotic cells: Keratinisation of individual cells, giving rise to eosinophilic cytoplasm and pyknotic nuclei

00 per 3 lower power fields $(x 10)$

11 per 3 lower power fields $(\times 10)$

22 per 3 lower power fields $(\times 10)$

$3>3$ per 3 lower power fields $(\times 10)$

5 Submucosal capillary proliferation

0 Flat, slightly wavey submucosal junction

1 Minimal increase in capillary loops, confined to lower half

2 Occasional capillary loop extending into upper half

3 Many capillary loops extending into upper half 
Fig 3 PAP positive sections for HPV nuclear viral antigens. Staining is always confined to superficial cell layers. (Counterstained with haemalum.) $\times 320$.

Table 3 Degree of koilocytosis

Abundance of koilocytes

1 Few, scattered throughout the epithelium

2 More abundant, but with one or two unaffected cells intervening

3 Koilocytes contiguous

\section{Extent of vacuolation}

1 Slight clearing to form a clear rim round the nucleus

2 Perinuclear clearing extending to half of cytoplasm

3 Extensive clearing, leaving only a thin rim of cytoplasm around cell periphery

sections of "B" koilocytes positive for virus were from separate patients. The one section that had proved difficult to assess as type " $A$ " or type " $B$ " (eventually assessed as type "B") was HPV negative. The extent of staining varied between the PAP positive sections and was found to correlate well with the total wart score for sections of " $A$ " koilocytes (table 5 ). In addition, sections of " $A$ " koilocytes positive for HPV had significantly higher total wart scores than sections of "A" koilocytes negative for HPV (fig 4 and table 4). Such an association was not found for "B" koilocytes.

For sections of " $A$ " and for sections of " $B$ " koilocytes, however, those positive for HPV were associated with higher degrees of koilocytosis than HPV negative sections (fig 4). The sections positive for HPV represented all degrees of dysplasia, from no dysplasia to severe dysplasia (table 5).

\section{Discussion}

DETECTION OF HPV IN KOILOCYTES; LIMITATIONS Virus was only detected in $20 \%$ of sections of " $A$ " koilocytes and in $10 \%$ of sections of " $B$ " koilocytes.
The low number of PAP positive sections is not surprising when the limitations of the PAP technique as a means of detecting HPV in cervical squamous epithelium are considered. The technique can only detect HPV where the viral antigen is expressed in reasonably high amounts. Cervical squamous epithelium, however, is only semipermissive for HPV, giving rise to inefficient viral reproductive cycles with low production of virions ${ }^{12}$ and low expression of the "late" genes required for production of viral antigen. ${ }^{1314}$ In addition, formalin fixation denatures antigen to some

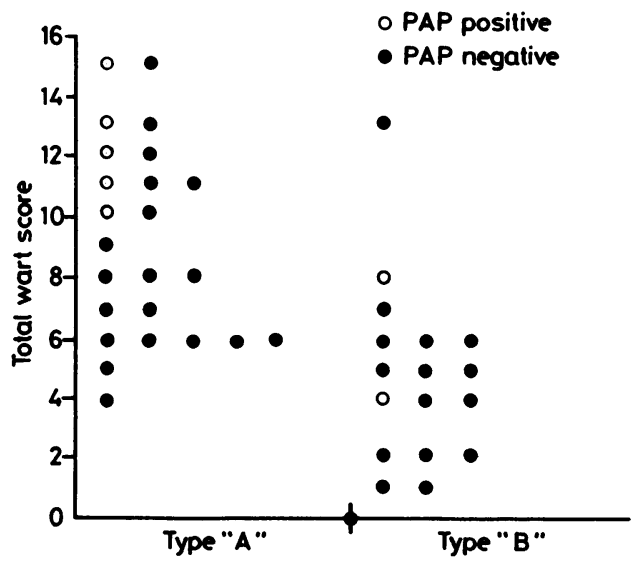

Fig 4 Total wart scores " $A$ " and " $B$ " koilocytes (PAP positive and negative). " $A$ " koilocytes are associated with higher total wart scores than " $B$ " koilocytes $(p=0.003$, Mann-Whitney $U$ test). For " $A$ " koilocytes, PAP sections are associated with higher total wart scores than PAP negative sections ( $p=0 \cdot 02$, Mann-Whitney $U$ test $)$. 


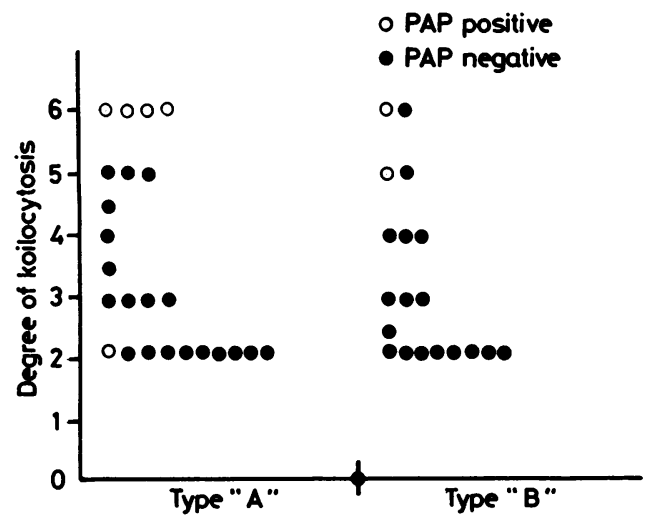

Fig 5 For both " $A$ " and " $B$ " koilocytes, PAP positive sections are associated with significantly higher degrees of koilocytosis than PAP negative sections ( $p=0.0016$, Mann-Whitney $U$ test).

degree. It must also be remembered that because viral antigen is expressed late ${ }^{15}$ in the viral reproduction cycle the PAP technique will not detect HPV infection in a latent, non-productive, or early phase.

Accordingly, tissue sections negative for virus by the PAP technique cannot be said to be "virus-free."

"A" AND "B" KOILOCYTES AS TWO POPULATIONS Despite the limitations of the PAP technique it was possible to establish that the original hypothesis of "A" koilocytes as HPV infected clear cells and "B" koilocytes as non-infected was invalid. HPV can be shown in both populations, and the differences in nuclear morphology cannot therefore be attributed simply to presence or absence of infection.
When a set of criteria (relevant to known HPV activities) are applied, however (the "wart score"), it is clear that the populations do differ. Population A has "wart features" in a more highly developed form than population $B$.

When, in addition, the criterion of associated dysplsia is considered, population $\mathbf{A}$ is significantly more dysplastic than $B$.

The results of the three approaches (antigen detection, wart score, and dysplasia) for clarifying the association between the two populations $\mathbf{A}$ and $\mathbf{B}$ are not necessarily conflictual. They can be reconciled in a credible modified hypothesis that views the type " $B$ " koilotype as part of an earlier, less developed infection than that of type "A". The modified hypothesis is entirely consistent with the enhanced "wart score" and dysplasia of the type "A" population, as both findings might reasonably be attributed to the longer exposure of the cells to the infecting virus. Populations $\mathbf{A}$ and $\mathbf{B}$ would thus exhibit differences of degree, or development, of infection rather than the more fundamental difference of the presence or absence of infection.

\section{HISTOLOGICAL MEANS OF DETECTING HPV}

Although it is proposed that " $\mathrm{B}$ " koilocyts are simply earlier manifestations of HPV infection than " $A$ " koilocytes, it is important not to regard all clear cells in cervical squamous epithelium as manifestations of HPV infection at different stages of infection, as clear cells can be found in cervical squamous epithelium for other reasons. This study has confirmed that the criterion of clear cell morphology alone cannot determine the presence of HPV. It did establish, however, that certain histological criteria can provide a reasonably reliable guide to the presence of HPV infection in sections of cervical squamous epithelium which dis-

Table 4 Degrees of dysplasia accompanying " $A$ " and " $B$ " koilocytes

\begin{tabular}{|c|c|c|c|c|c|}
\hline & \multicolumn{5}{|c|}{ Degree of dysplasia } \\
\hline & Absent & Mild & Moderate & Severe & CIS \\
\hline $\begin{array}{l}A \text { koilocytes } \\
B \text { koilocytes }\end{array}$ & $\begin{array}{r}0 \\
10\end{array}$ & $\begin{array}{l}5 \\
5\end{array}$ & $\begin{array}{r}12 \\
2\end{array}$ & $\begin{array}{l}5 \\
2\end{array}$ & $\begin{array}{l}1 \\
0\end{array}$ \\
\hline
\end{tabular}

Table 5 Properties of sections staining positively for HPV

\begin{tabular}{|c|c|c|c|c|}
\hline Section* & $P A P$ staining & Total wart score & Degree of koilocytosis & Associated dysplasia \\
\hline $\begin{array}{l}\text { A1 } \\
\text { A2 } \\
\text { A6 } \\
\text { A10 } \\
\text { A11 } \\
\text { B2 } \\
\text { B19 }\end{array}$ & $\begin{array}{l}+++ \\
++t \\
++ \\
+ \\
+ \\
++ \\
++\end{array}$ & $\begin{array}{r}15 \\
13 \\
12 \\
10 \\
11 \\
4 \\
8\end{array}$ & $\begin{array}{l}6 \\
6 \\
6 \\
2 \\
6 \\
5 \\
6\end{array}$ & $\begin{array}{l}\text { Mild } \\
\text { Moderate } \\
\text { Severe } \\
\text { Severe } \\
\text { Mild } \\
\text { None } \\
\text { Severe }\end{array}$ \\
\hline
\end{tabular}

*Prefix 'A' = 'A' koilocyte series; prefix 'B' = 'B' koilocyte series; sections A1 and A2 were from the same patient, but were different biopsy specimens. 
play koilocytes. For sections of " $A$ " koilocytes, a total wart score comprising a number of known features of wart virus infection in the cervix and elsewhere provides a reasonably reliable indication of the likelihood of findings virus in the tissue. For sections of " $A$ " and "B" koilocytes, the degree of koilocytosis present provides a reasonable indicator of the presence of HPV infection.

It would seem, therefore, that when attempting to determine the presence of HPV by simple histological means, undue weight should not be placed on the clear cells and their individual morphology but that the cervical squamous epithelium should be evaluated as a whole-as attempted in the "wart score" and degree of koilocytosis.

\section{KOILOCYTES AND CER VICAL CANCER}

If, indeed, as proposed, "B" koilocytes are an earlier stage of " $A$ " koilocytes the finding that " $A$ " koilocytes are associated with greater degrees of epithelial dysplasia than "B" koilocytes supports a potential role for HPV in cervical cancer. It suggests that as the virus becomes more established it causes increasing dysplastic changes, which in turn, are at risk of progressing to CIS, and even to invasive carcinoma.

\section{FUTURE PROSPECTS}

The immunoperoxidase technique discussed here is an insensitive method of detecting HPV. It would be interesting, therefore, to continue to work using DNA probes to different types of HPV. It may be that " $A$ " and "B" koilocytes are associated with different types of virus, which may, in turn, have different propensities for cervical dysplasia and malignancy.

I am grateful to Dr Stewart Fletcher for assistance and to Mrs Margo Boyle of the department of pathology, University of Edinburgh, for typing the manuscript.

\section{References}

1 Koss LG, Durfee GR. Unusual patterns of squamous epithelium 음 of the uterine cervix. Cytological and pathological study of $\Rightarrow$ koilocytotic atypia. Ann NY Acad Sci 1956;63:1245-61.

2 Woodruff JD, Peterson WF. Condyloma acuminatum of the cervix. Am J Obstet Gynecol 1958;75:1353-61.

3 Meisels A, Fortin R, Roy M. Condylomatous lesions of the cervix. II. Cytologic, colposcopic and histopathologic study. Acta Cytol 1977;21:379-90.

4 Reid R, Stanhope R, Herschmann B, et al. Genital warts and 은 cervical cancer. I. Evidence of an association between sub- ڤ) clinical papillomavirus infection and cervical malignancy. Can- $\vec{O}$ cer 1982;50:377-87.

5 Syrjanen K. HPV lesions in association with cervical dysplasias and neoplasias. Obstet Gynecol 1983;62:617-24.

6 Zoler ML. Human papilloma virus linked to cervical (and other) cancers. JAMA 1983;249:2997-9.

7 De Girolami E. Perinuclear halo versus koilocytotic atypia. $O b$ stet Gynecol 1967;29:479-87.

8 Luna LG, Cawley M. Significantly morphologic and chromatic $\dot{\omega}$ alterations produced by histopathological techniques. In: $A d-\omega$ vances in automated analysis. Vol 1. Miami: Thurman Associ- $\omega$ ates, 1970:143-52.

9 Govan ADT, Haines RM, Langley FA, Taylor CW, Woodcock AS. The history and cytology of changes in the epithelium of the cervix uteri. J Clin Pathol 1969;22:383-95.

10 Fletcher S. Histopathology of papilloma virus infection of the cervix uteri: the history, taxonomy, nomenclature and reporting of koilocytic dysplasias. J Clin Pathol 1983;36:616-24.

11 Kurman RJ, Shah KH, Lancaster WD, et al. Immunoperoxidase localisation of papillomavirus antigens in cervical dysplasia . and uvlvar condylomata. Am J Obstet Gynecol 1981;140:931-5.

12 Fletcher $\mathrm{S}$, Norval $M$. On the nature of the deep cellular disturbance in human papilloma virus infection of the squamous cervical epithelium. Lancet 1983;ii:546-8.

13 Dunn A, Ogilvie M. Intranuclear virus particles in human genital wart tissues. Observations on the ultrastructure of the epidermal layer. J Ultrastruct Res 1968;22:282-95.

14 Oriel JD, Almeida JD. Demonstration of viral particles in human genital warts. British Journal of Venereal Disease 1970;46:37-42.

15 Amtmann E, Sauer G. Bovine papilloma virus transcription. Polyadenylated RNA species and assessment of the direction of transcription. J Virol 1982;43:59-66.

Requests for reprints to: Karen McLeod, Department of Pathology, University of Edinburgh Medical School, Teviot Place, Edinburgh EH8 9AG, Scotland. 